\title{
Association of Acute Lymphoblastic Leukemia with Unilateral Facial Palsy: A Rare Presentation
}

\author{
Vipul Taneja ${ }^{1}$, Goud Raghvendra ${ }^{2}$, Kusum Mahajan ${ }^{3}$, A. K. Bhardwaj ${ }^{4}$, \\ Rishu Malik ${ }^{5}$
}
${ }^{1}$ Assistant Professor, Dept of Pediatrics, Maharishi Markandeshwar Institute of Medical Sciences and Research.
${ }^{2}$ Junior Resident ( $3^{\text {rd }}$ Year), Dept of Paediatrics, Maharishi Markandeshwar Institute of Medical Sciences and Research.
${ }^{3}$ Professor \& HOU, Dept of Paediatrics, Maharishi Markandeshwar Institute of Medical Sciences and Research, ${ }^{4}$ HOD, Dept of Paediatrics, Maharishi Markandeshwar Institute of Medical Sciences and Research.
${ }^{5}$ Assistant Professor, Al-Fala School of Medical Sciences and Research Center.

Corresponding Author: Vipul Taneja

\begin{abstract}
Acute lymphoblastic leukemia (ALL) is the most common pediatric cancer. Survival probability of pediatric ALL had been 10-20\%, but the most recent clinical trials with multiagent chemotherapy have achieved overall survival probability of better than $80 \%$. This is achieved because of better supportive care, treatment stratification based on relapse risk, and the biological features of leukemic cells. Diagnosis of ALL was based principally on morphological identification of leukemic blasts in bone marrow, and immunophenotype assessment by flow cytometry is necessary, and most pediatric ALL cases are clinically classified as B-cell precursor, T-cell ALL, or mature B-cell types.
\end{abstract}

Keywords: Acute Lymphoblastic Leukemia, ALL, Unilateral Facial palsy, pediatric ALL

\section{CASE REPORT}

A 16-year-old adolescent male was brought with complaints of skeletal pain and fever for 2 months. Skeletal pain was gradually progressive in intensity which got partly relieved on pain medication. No consistent history of early morning joint stiffness, swelling of joint or pain limited to distal phalangeal joints.

The next important symptom was fever responding to medication. Fever was high grade, intermittent no association with chills.

\begin{tabular}{|l|l|}
\hline Differential & count \\
\hline Polymorph & 16 \\
\hline Lymphocyte & 46 \\
\hline Eosinophils & 00 \\
\hline Monocytes & 02 \\
\hline Blast cells & 36 \\
\hline
\end{tabular}

On clinical examination child was severely pale, non-icteric, with palpable lymph nodes in cervical and axillary region.
There was unilateral facial palsy with preserved hearing. Liver is palpated $4 \mathrm{~cm}$ below right coastal margin, spleen $2 \mathrm{~cm}$ below left coastal margin.

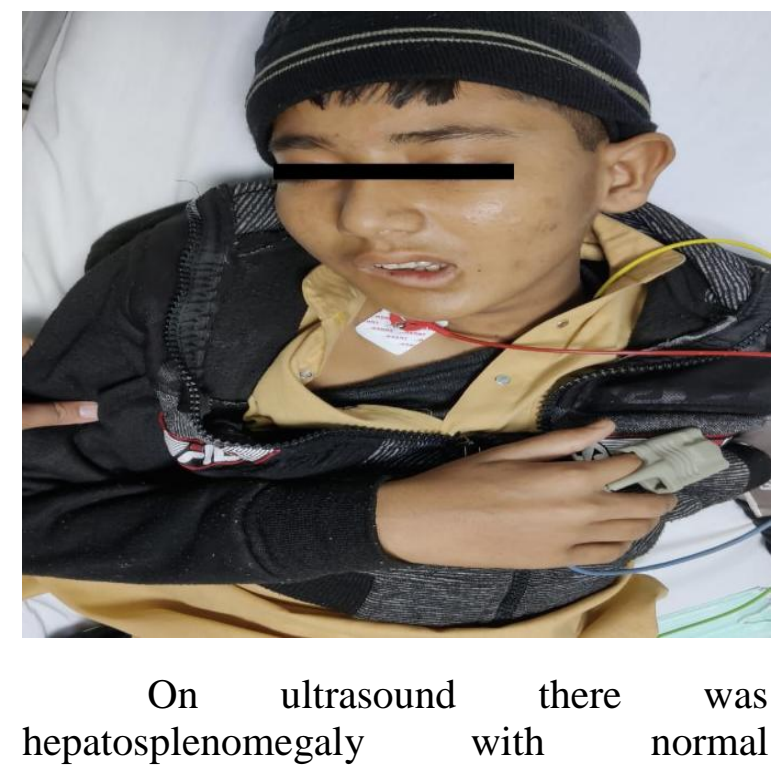


Vipul Taneja et.al. Association of acute lymphoblastic leukemia with unilateral facial palsy: a rare presentation.

echotexture of liver. Hb was $6.2 \mathrm{mg} / \mathrm{dl}$, with TLC $11,200 / \mathrm{mm}^{3}$ Platelet:20,000 cells $/ \mathrm{mm}^{3}$.

Peripheral blood smear high nuclearcytoplasmic ratio, large nucleoli, and moderate amount of cytoplasm with granules. Occasional nucleated RBC morphologically appearing as Acute Lymphoblastic Leukemia.

Kidney function and liver function tests were normal.

\section{DISCUSSION}

Acute lymphoblastic leukemia (ALL) is the most common pediatric cancer. It has a slight male preponderance, with peak incidence between 1-4 years. The most recent clinical trials have achieved overall survival probability of better than $80 \%^{1,2}$. Symptoms of ALL are nonspecific with fever, bone pain, lymphadenopathy, mediastinal mass. Diagnosis of ALL was based principally on morphological identification of leukemic bone marrow blasts exceeding 25\%.Immunophenotype assessment by flow cytometry (FCM) is necessary. Clinical features of T-cell ALL are different from B-cell ALL. Prognosis of T-cell ALL is poor compared to B cell ALL.

Treatment duration is 2-3 years consisting of induction, consolidation, and maintenance therapy. Allogenic stem cell transplant is also indicated in high risk cases $^{3}$.

Acknowledgement: None

Conflict of Interest: None

Source of Funding: None

\section{REFERENCES}

1. Kato M, Kurata M, Kanda J, et al. Impact of graft-versus-host disease on relapse and survival after allogeneic stem cell transplantation for pediatric leukemia. Bone Marrow Transplant. 2019;54:68-75.

2. Arico M, Valsecchi MG, Camitta B, et al. Outcome of treatment in children with Philadelphia chromosome-positive acute lymphoblastic leukemia. N Engl J Med. 2000; 342:998-1006.

3. Stern M, de Wreede LC, Brand R, et al. Sensitivity of hematological malignancies to graft-versus-Host effects: an EBMT megafile analysis. Leukemia. 2014;28: 2235-40.

How to cite this article: Taneja T, Raghvendra $\mathrm{G}$, Mahajan $\mathrm{K}$ et.al. Association of acute lymphoblastic leukemia with unilateral facial palsy: a rare presentation. Int $J$ Health Sci Res. 2021; 11(8): 79-80. DOI: https://doi.org/10. 52403/ijhsr.20210811 